\title{
Layer-by-layer thin films of polyaniline alternated with natural rubber and their potential application as a chemical sensor
}

\author{
C. R. Cena ${ }^{1}$ - L. F. Malmonge ${ }^{2}$ J. A. Malmonge ${ }^{2}$
}

Received: 18 July 2016 / Accepted: 19 December 2016/Published online: 27 December 2016

(C) Springer Science+Business Media Dordrecht 2016

\begin{abstract}
Self-assembled films of polyaniline (PAni) alternated with natural rubber (NR) were successfully produced by layer-by-layer self-assembly technique (LbL), by using the latex of natural rubber obtained from the Hevea-brasiliensis tree. The centrifuged NR latex was used without any previous treatment. The influence of $\mathrm{pH}$ on the adsorption kinetics and film growth was evaluated. The films presented a typical linear growth, showing a constant adsorption of material in each deposition step. The FTIR spectroscopy study confirmed the presence of rubber chains (cis-1,4-poly-isoprene) on the LbL films. The morphological characterizations showed great roughness and a spherical shape of the NR particles as a predominant characteristic on the film's surface. Finally, the potential use of the films as a chemical sensor was identified in our tests.
\end{abstract}

Keywords Self-assembly $\cdot$ Polyaniline $\cdot$ Natural rubber $\cdot$ Thin film $\cdot$ Chemical sensor

\section{Introduction}

The science of thin films has an essential role in technology, due to the versatility of applications and unique electrical,

C. R. Cena

cicero.cena@ufms.br

1 UFMS - Universidade Federal do Mato Grosso do Sul, Instituto de Física, Cidade Universitária s/n, PO box 549, Campo Grande, MS 79070-900, Brazil

2 Departamento de Física e Química, Faculdade de Engenharia, UNESP - Univ. Estadual Paulista, Campus de Ilha Solteira, Ilha Solteira, SP, Brazil optical and thermal properties exhibited at nanoscale. In the last few years, many studies have been performed by using polyaniline (PAni) as a sensitive material for many applications [1-3], and natural rubber (NR) has been investigated for its potential for biomedical applications [4, 5]. Recently, the search for biopolymers to develop thin films for sensor applications has aimed to replace synthetic materials, making sensors more versatile, biodegradable, and non-toxic, with lower processing costs [1].

In this scenario, the layer-by-layer self-assembly technique (LbL) [6] is one of the most common and inexpensive techniques employed to produce thin films, which has a good control of thickness and molecular architecture. Different mechanisms can be used to build up multilayer films; basically, the LbL technique consists of the alternate adsorption of molecular layers via electrostatic interaction, but can also be driven by hydrogen bonding or bio-specific interactions [7].

Polyaniline is a conductive polymer that has been studied extensively, owing to its excellent chemical stability in a doped state, solubility, low cost, easy processing, and doping when compared with other polymers [8], and it can also be employed as a sensitive material for sensor applications [8-10]. Thin LbL films of polyaniline alternated with a large variety of other polymers have already been produced [9-14], including synthetic rubber for pressure sensor materials [15], but, to our knowledge, this is the first report on the fabrication of LbL films of PAni alternated with NR evaluated as a chemical sensor. Natural rubber is constituted by spherical particles ranging from $5 \mathrm{~nm}$ to $3 \mu \mathrm{m}$, surrounded by proteins, lipids, and long chains of fatty acid, which confers a negative charge to the particles; this configuration is stable only for pHs higher than 5.0. The basic constituents of NRs are polymer chains of cis-1,4-poly-isoprene with a high molecular weight [16]. The main 
advantage of NR is that it presents elasticity, flexibility, resilience and it is a common natural polymer that is easy to handle. It can be an inexpensive and easy alternative for producing thick or thin LbL films with interesting morphological and mechanical properties [5].

In this work, LbL films of PAni alternated with NR latex were produced by employing PAni doped and undoped, and the results showed that in both cases, the film presented similar physical-chemical characteristics but the morphology was quite different. Its potential application as a chemical sensor was evaluated for different analytes, by using capacitance measurement.

\section{Experimental details}

\section{Polyaniline synthesis and solution preparation}

Polyaniline was chemically synthesized with ammonium peroxidisulfate $(\mathrm{NH} 4)_{2} \mathrm{~S}_{2} \mathrm{O}_{8}$ in an aqueous $\mathrm{HCl}$ solution $(1.0 \mathrm{M})$, as described elsewhere [17]. The monomer to oxidant ratio was kept at $4: 1$ with polymerization carried out at $0{ }^{\circ} \mathrm{C}$ for about $3 \mathrm{~h}$ to yield the polymer in the emeraldine base form (EB). Dedoping was performed by treatment with a $0.1 \mathrm{M}$ ammonium hydroxide solution for $16 \mathrm{~h}$ at room temperature. The polymer was then dried under a dynamic vacuum for $24 \mathrm{~h}$ at room temperature.

The PAni solutions were prepared by the dissolution of PAni in N,N-Dimethylacetamide (DMAc) under constant stirring for $16 \mathrm{~h}$; the final solution was filtered to remove undissolved PAni. Five parts of deionized water in volume was added to the final solution before being used in the deposition process. The presence of water in the solution facilitates the deposition process [18] and this ratio of solvent to water was determined by a solution stability study [19]. Finally, the concentration of the solution was adjusted by using LambertBeer's law [20], by measuring the solution absorption in the $\mathrm{UV}$-vis region.

\section{Natural rubber and solution preparation}

Natural rubber (NR) latex was collected from Hevea brasiliensis trees (Clone RIMM 600) [Experimental Farm of the University of São Paulo State (UNESP), campus de Ilha Solteira, Brazil] and stabilized in a commercial solution of ammonium hydroxide. The latex was centrifuged at $12,500 \mathrm{rpm}$ for $20 \mathrm{~min}$ at $4{ }^{\circ} \mathrm{C}$ to remove impurities and others no rubber constituents [21]. The latex was diluted in deionized water and the $\mathrm{pH}$ adjusted to 10 by using an ammonium hydroxide solution $1 \mathrm{M}$. The final solution was held at a low temperature $\left(\sim 5{ }^{\circ} \mathrm{C}\right)$ until being used. The NR solution, prepared for the deposition process, was adjusted with a concentration of $1.0 \mathrm{~g} / \mathrm{L}$ and $\mathrm{pH}$ around 7.0.

\section{Film deposition and characterization}

The film deposition was performed by the self-assembly technique on glass substrates, previously cleaned by the RCA method [22]. The first layer of the film was formed by immersing the substrate into the PAni $(0,8 \mathrm{~g} / \mathrm{L})$ solution followed by the adsorption of the natural rubber particles; at each deposition step, the film was washed in deionized water (with the same $\mathrm{pH}$ as the previous solution) and dried with nitrogen pressured gas. Films with 10 bilayers were obtained by repeating the previous procedures.

The isosbestic points of the PAni were determined by UVvis spectroscopy of the PAni/DMAc/ $\mathrm{H}_{2} \mathrm{O}$ solution at different pHs. The adsorption kinetics [23] were carried out by measuring the absorbance of the films at $464 \mathrm{~nm}$ (an isosbestic point). The amount of material deposited, $\Gamma\left(\mu \mathrm{g} / \mathrm{cm}^{2}\right)$, in each step was estimated according to the Lambert-Beer law $A=c \varepsilon b$, where $\varepsilon\left(\mathrm{m}^{2} / \mathrm{g}\right)$ is the molar extinction coefficient, and $c(\mathrm{~g} / \mathrm{L})$ and $b(\mathrm{~mm})$ are the solution concentration and path length, respectively [20].

UV-vis and Infrared spectroscopy (FTIR) analyses were performed using a Carry 50 spectrophotometer and a NEXUS 670 spectrophotometer, respectively. The FTIR spectra of pure PAni ( $\mathrm{KBr}$ pellets containing about $2 \%$ wt. of PAni powder) and NR (casting the NR/toluol solution on the disk surface of $\mathrm{KBr}$ ) were measured by using the transmittance method. The PAni/NR LbL thin film was deposited on a zinc selenite $(\mathrm{ZnSe})$ substrate with 10 bilayers for the FTIR transmittance measurement.

The film's morphology was studied in a $10 \times 10 \mu \mathrm{m}$ area with Atomic Force Microscopy (AFM), from Digital Instruments Nanoscope III, by using the intermittent mode, and also by Scanning Electron Microscopy with a field emission gun (FEG-SEM) from Zeiss supra 35, the images was obtained by using a SE detector, beam aceleration at $25 \mathrm{kV}$ and magnification around $50 \mathrm{kX}$.

\section{Tests as a potential chemical sensor}

To determine the potential of the films as a chemical sensor, tests were performed by using PAni/NR (undoped) thin films with 10 bilayers deposited on a glass substrate with interdigitalized gold electrodes. The circuit employed in this study contained 50 pairs of electrodes; their dimensions were standardized at $10 \mu \mathrm{m}$ of length, distanced by $10 \mu \mathrm{m}$ and with $0.1 \mu \mathrm{m}$ of thickness.

The sensitivity of the films as sensors was studied by monitoring changes in their capacitance after being immersed for $5 \mathrm{~min}$ in different analyte solutions that simulated different tastes. The tests were performed by using different analytes: 
saccharose (sweet), caffeine (bitter), $\mathrm{HCl}$ (acid) and $\mathrm{NaCl}$ (salt). First, the thin film's response was measured in pure deionized water, as reference. Then the thin film's capacitance was measured in the frequency range of $0.01-10,000 \mathrm{kHz}$ by using an impedance analyzer (Hewlett Packard 4192A). After being used in a specific analyte, the thin film was washed in deionized water for $5 \mathrm{~min}$ and dried with nitrogen before being used again.

\section{Results and discussion}

The spectra of PAni in the DMAc/ $\mathrm{H}_{2} \mathrm{O}(1: 5)$ solution at different states of oxidation (or pHs) are shown in Fig. 1. Two absorption bands can be observed for $\mathrm{pH} 5.0$ (320 and $600 \mathrm{~nm}$ ), which are characteristic of PAni emeraldine base form [24]. For $\mathrm{pH} 2.5$, the shoulder at $400 \mathrm{~nm}$ and the free carrier tail above $600 \mathrm{~nm}$, related to the doping process, are assigned as polaron bands [24]. The free carrier tail is indicative of secondary doping effects, which result in a more extended chain conformation, allowing a more delocalized polaronic band [24]. The points that intersect the spectra are known as isosbestic points; in this case, there are 3 isosbestic points at 365,464 , and $673 \mathrm{~nm}$. The isosbestic point at $464 \mathrm{~nm}$ was used to evaluate the amount of deposited material in the PAni/NR film in each self-assembled step.

The adsorption kinetics study was performed by monitoring the film's absorption at $464 \mathrm{~nm}$ in each step of the deposition. The amount of adsorbed material on the glass substrate was estimated by using Beer's law. The mechanism of adsorption for the PAni chains at lower pHs (under $\mathrm{pH} 4$, doped PAni) is usually driven by electrostatic

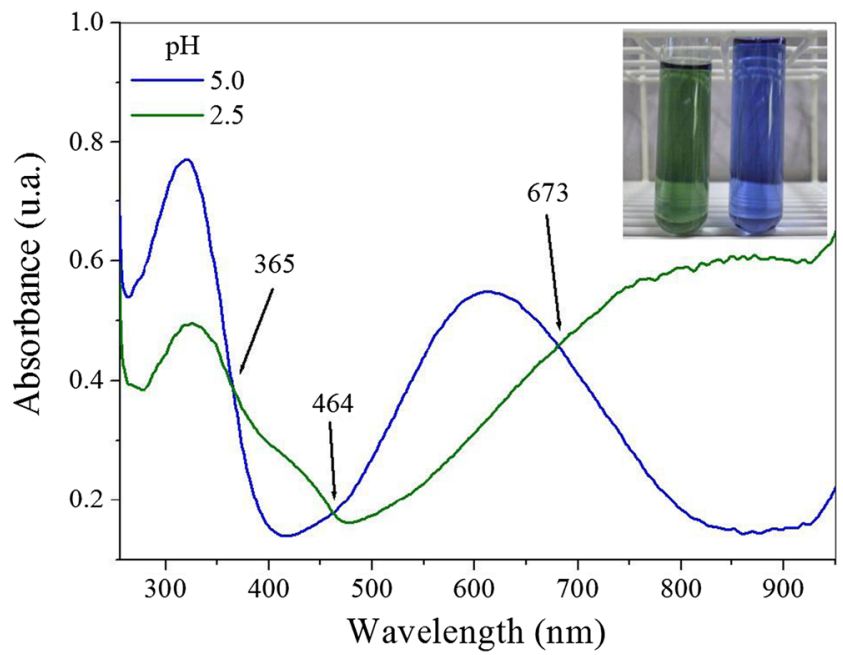

Fig. 1 UV-vis spectra of PAni/DMAc/ $/ \mathrm{H}_{2} \mathrm{O}$ at different $\mathrm{pHs}$, as indicated. In the inset is a photograph of the PAni solution with $\mathrm{pH} 2.5$ (green color) and $\mathrm{pH} 5.0$ (blue color) interactions, because the polymeric chains acquire positively charged sites; consequently, the polymeric chains exhibit a more elongated conformation due to the electrostatic repulsion between the charged sites [18, 25]. However, above $\mathrm{pH} 4$, the undoped PAni does not exhibit charged sites; consequently, the polymeric chains are in a more compact conformation, and the adsorption mechanism can be driven by secondary interactions or even adsorbed as a neutral material [26-28]. Thus, the PAni $\mathrm{pH}$ solution is a decisive parameter that provides a charged or uncharged polymeric chain and modifies the mechanism parameters. On the other hand, the $\mathrm{pH}$ of the NR solution is directly related to the proteic membrane's stability, which is responsible for the spherical form of the NR particles and its negative charge characteristic, and at a lower $\mathrm{pH}$ can disrupt the proteic membrane, causing coagulation $[16,29,30]$. Therefore, evaluating the LbL film fabrications as functions of the $\mathrm{pH}$ solutions is an important step for producing films with better quality.

Figure 2 shows the results obtained for the adsorption kinetics of PAni's first layer, with the PAni concentration of $0.8 \mathrm{~g} / \mathrm{L}$ and $\mathrm{pHs}$ of 2.5 and 5.0. The proper choice of these $\mathrm{pHs}$ is correlated to different mechanisms of adsorption; that could be related to charged and uncharged PAni chains, usually, electrostatic interaction (doped PAni - $\mathrm{pH} 2.5$ ) and secondary interactions (undoped PAni - $\mathrm{pH} 5.0$ ), respectively $[18,23,26]$.

In Fig. 2, the adsorption process of PAni's first layers occurs at two different steps. The two-step process is in accordance with results obtained by Raposo et al. [23], the frist one should correspond to the polymer molecules being driven toward the substrate due to electrostatic interaction, while the second one correspond to the rearrangement of polymer

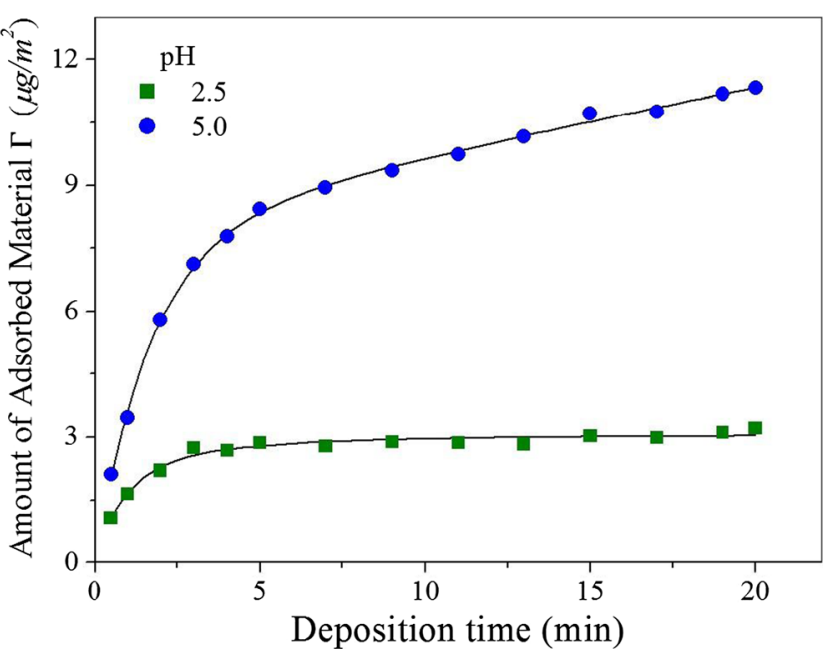

Fig. 2 Study of the adsorption kinetics of PAni's first layer, on a glass substrate, at different $\mathrm{pHs}$ 
molecules on the substrate. The results can be fit if two exponential functions are superimposed, eq. (1).

$A=k_{1}\left(1-e^{-\frac{t}{\tau_{1}}}\right)+k_{2}\left(1-e^{-\left(\frac{t}{\tau_{2}}\right)^{n}}\right)$

where $A$ is the absorbance, $k_{1}, k_{2}$ and $n$ are constants, and $\tau_{1}$ and $\tau_{1}$ are the characteristic times. Table 1 shows the parameters used for fitting the data of Fig. 2.

The first exponential corresponds to a first-order kinetics, with characteristic times $(\tau)$ around $1-2 \mathrm{~s}$, the adsorption process in this case is relatively fast, occurring in the first few seconds of the immersion of the substrate within the PAni solution, indicating good interaction between the polymer and the substrate [25]. The second exponential can be associated by a so-called Johnson-Mehl-Avrami function with $\mathrm{t}^{\mathrm{n}}$ in the exponential and with characteristic times $(\tau)$ around $200-350$ s. As evidencied by the results, Fig. 2, in the doped PAni $(2.5 \mathrm{pH})$ with a positively charged chain, the adsorption process occurs more quickly than the undoped PAni, and reaches the equilibrium plateau before $3 \mathrm{~min}$ of immersion; after that the adsorption process became self-limited by electrostatic repulsive interactions between the adsorbed chains and the chains in the solution, showing final amount of adsorbed material $2,94 \mu \mathrm{g} / \mathrm{m}^{2}[23,31]$. Otherwise, the undoped PAni adsorption process is not self-limited and the amount of adsorbed material is much higher than in the doped PAni, showing final amount of adsorbed material 9,62 $\mu \mathrm{g} / \mathrm{m}^{2}$. In both cases, the adsorption process occurs faster, before $5 \mathrm{~min}$, and usually the adsorption will cease due to the mechanical instability of the adsorbed layer [25, 31].

The initial tests of producing LbL films with PAni (5.0 $\mathrm{pH}$ ) alternated with $\mathrm{NR}$ revealed that $5 \mathrm{~min}$ of immersion was not enough to adsorb a homogeneous layers. After further testing, we found that when we used $10 \mathrm{~min}$ of adsorption time in a single step with the same solution, linear growth was observed, Fig. 3. The LbL films produced with doped PAni $(2.5 \mathrm{pH})$ showed linear growth with 3 min of immersion time; during the growth process, the water molecules can attached to the substrate surface, reducing the number of sites [25] for PAni/NR adsorption. The charged polymeric chain was able to overcome the diffusion of the water molecules and was more quickly adsorbed on the substrate surface, forming a homogenous monolayer that covered the entire surface before the

Table 1 Parameters used in eq. 1 for fitting the experimental data of Fig. 2

\begin{tabular}{llllll}
\hline $\mathrm{Ph}$ & $\mathrm{k}_{1}$ & $\tau_{1}(\mathrm{~s})$ & $\mathrm{k}_{2}$ & $\tau_{2}(\mathrm{~s})$ & $\mathrm{n}$ \\
\hline 2,5 & 0,00275 & 1,0797 & 0,02817 & 224,48 & 1,76 \\
5,0 & 0,00649 & 1,7057 & 0,02687 & 287,84 & 0,61 \\
\hline
\end{tabular}

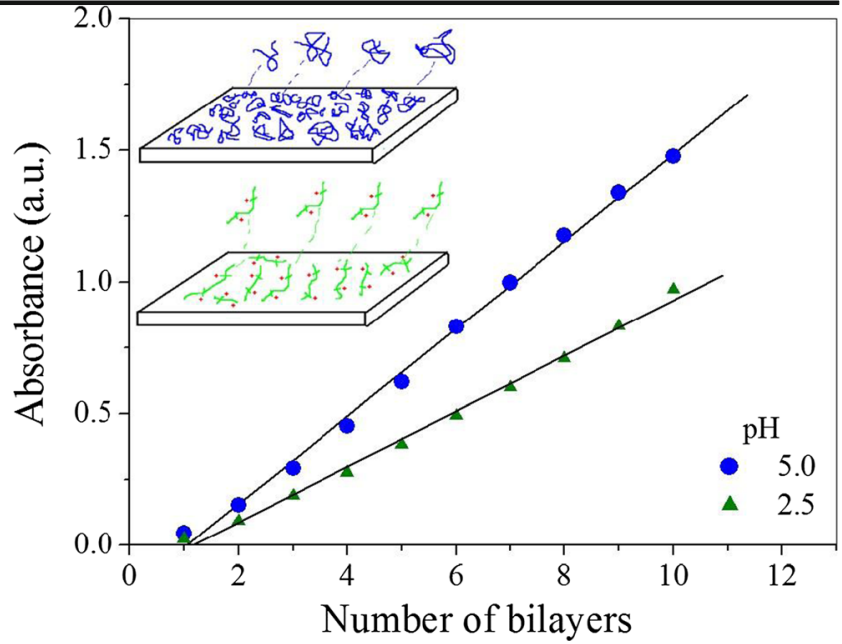

Fig. 3 Study of film PAni/NR growth at different $\mathrm{pHs}$

reactive sites on the substrate surface became inactive due to the attachment of water molecules.

The $\mathrm{pH}$ dependence in the material's adsorption was evidenced by our film growth studies, as shown in Fig. 3. The immersion time was standardized at $10 \mathrm{~min}$ for both $\mathrm{pHs}$ analyzed. The NR latex was employed with $\mathrm{pH} 7.0$ and a concentration of $1.0 \mathrm{~g} / \mathrm{L}$. The amount of adsorbed material increased linearly with the number of bilayers for both $\mathrm{LbL}$ films, being higher at higher pHs. After 10 bilayers, some or even no additional material was adsorbed, probably due to the high amount of material present in the film. The system became self-limited by the mechanical instability of the layers or even electrostatic repulsion, as discussed by the literature [25, $31]$.

The amount of material adsorbed at $5.0 \mathrm{pH}$ was much higher than that at $2.5 \mathrm{pH}$. The undoped PAni attach to the substrate as a neutral polymer and there is no electrical repulsion between the chains that exhibit a more compact coil conformation, which enables a dense film formation, and consequently a large amount of material will be deposited. The adsorption mechanism for PAni deposited at $\mathrm{pH} 2.5$ is driven by electrostatic interaction, exhibiting an extended coil conformation $[28,32]$ and occupying more space, and due to the electrostatic repulsion between the chains, less material is necessary to cover the substrate surface, as illustrated in the scheme inset in Fig. 3.

The morphology of the natural rubber was investigated by using FEG-SEM microscopy. For that, highly diluted NR latex at $\mathrm{pH} 7.0$ was cast on a silicon substrate, dried at room temperature and coated with a thin layer of gold. As shown in Fig. 4(a), we clearly see a spherical shape of NR with various diameter sizes. This result is in accordance with those found in the literature [29]. The monolayers of PAni self-assembled films were also investigated with undoped PAni, Fig. 4(b), and doped PAni, Fig. 4(c). The undoped PAni films were adsorbed in a compact conformation, with a huge porous and holes formed across the surface. The doped PAni showed 
Fig. 4 FEG-SEM images and the respective chemical structures of (a) natural rubber particles deposited by casting; the first layer of (b) PAni undoped and (c) PAni doped deposited by selfassembly technique. AFM images of self-assembled LbL thin films PAni/NR with 10 bilayers (d) PAni pH 5.0 and (e) PAni pH 2.0
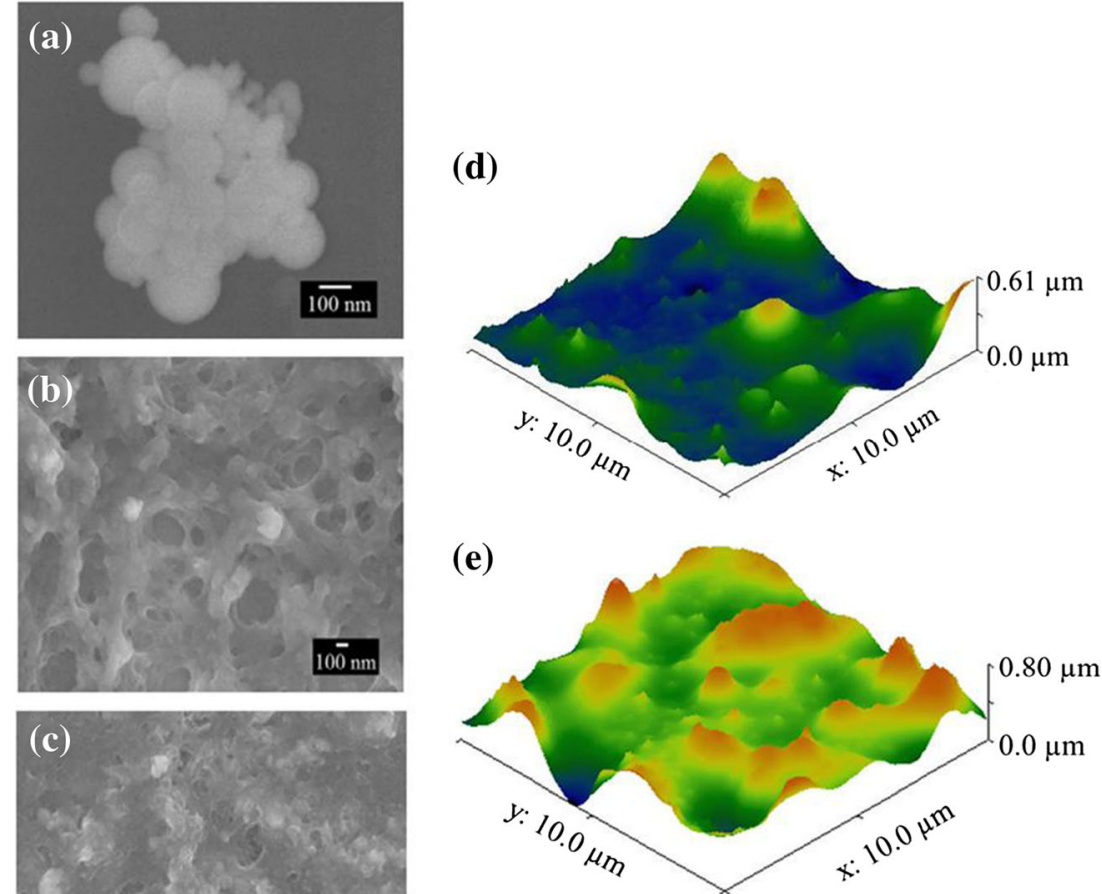

a more homogeneous structure, with few defects in a dense film formation.

The PAni/NR LbL thin films with 10 bilayers, obtained from PAni at pH 5.0 (Fig. 4(d)) and pH 2.5 (Fig. 4(e)), were characterized by AFM. A quite irregular surface with evidence of globular particles, probably due to NR particles, were observed in the films. The RMS roughness value was calculated in a single area of $100.0 \mu \mathrm{m}^{2}$ by Gwyddion software analysis. The results for the PAni/NR LbL films deposited at $\mathrm{pH} 5.0$ and $\mathrm{pH} 2.5$ showed RMS roughness around $87.7 \mathrm{~nm}$ and $107 \mathrm{~nm}$, respectively.

The LbL film roughness decreased with the increasing amount of adsorbed material. The adsorption of a single layer of undoped PAni showed a large number of pores (Fig. 4(b)) compared to doped PAni (Fig. 4(c)). These pores can be filled with NR rubber particles, resulting in a LBL film with smaller roughness.

The FTIR spectra obtained for the PAni/NR LbL thin films and the cast films of undoped PAni and natural rubber are shown in Fig. 5 and the assignment of principal vibration modes are summarized in Table 2. The results obtained for PAni (Fig. 5(c)) and for natural rubber (Fig. 5(b)) are in accordance with the literature $[30,32]$. The characteristic absorption peaks of PAni $\left(1587,1495\right.$, and $1305 \mathrm{~cm}^{-1}$ ) and NR $\left(2962,2927,2852\right.$, and $\left.1450 \mathrm{~cm}^{-1}\right)$ can also be found in the spectra of the PAni/NR LbL thin films (Fig. 5(a)). The spectrum was a simple overlap of the spectrums of its constituents, indicating that there was no chemical interaction between NR and PAni.

The LbL thin films were evaluated as chemical sensors by monitoring their electrical properties (capacitance vs.

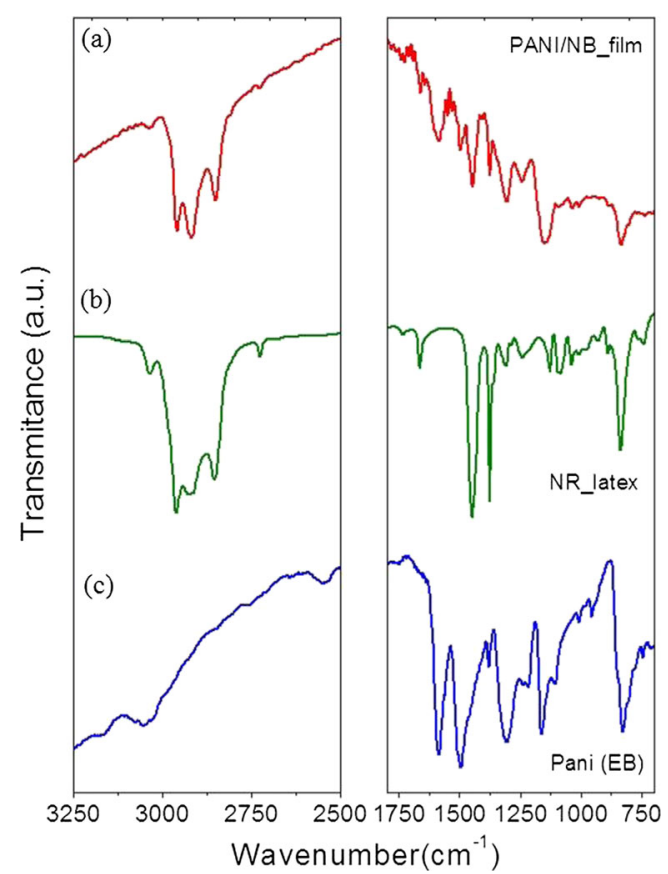

Fig. 5 FTIR spectra of (a) PAni (undoped)/NR LbL thin film with 10 bilayers, (b) natural rubber, and (c) undoped PAni 
Table 2 Assignments of FTIR wavenumbers identified in the samples $[30,33]$

\begin{tabular}{lccc}
\hline Vibrational Assignment & \multicolumn{2}{l}{ Wavenumber $\left(\mathrm{cm}^{-1}\right)$} \\
\cline { 2 - 4 } & PAni & LbL film & NR \\
\hline = CH stretching & & 3035 & 3033 \\
$\mathrm{C}-\mathrm{H}$ stretching of $\mathrm{CH}_{3}$ & & 2962 & 2962 \\
$\mathrm{C}-\mathrm{H}$ stretching of $\mathrm{CH}_{2}$ & & 2927 & 2927 \\
$\mathrm{C}-\mathrm{H}$ stretching of $\mathrm{CH}_{3}$ and $\mathrm{CH}_{2}$ & & 2854 & 2855 \\
$\mathrm{~N}=\mathrm{Q}=\mathrm{N}$ stretching & 1587 & 1585 & \\
$\mathrm{C}=\mathrm{C}$ stretching & & 1664 & 1664 \\
$\mathrm{~N}-\mathrm{B}-\mathrm{N}$ stretching & 1495 & 1496 & \\
$\mathrm{C}-\mathrm{H}$ bending of $\mathrm{CH}_{2}$ & & 1448 & 1450 \\
$\mathrm{C}-\mathrm{H}$ bending of $\mathrm{CH}_{3}$ & & 1375 & 1375 \\
$\mathrm{~N}-\mathrm{H}$ bending & 1303 & 1305 & \\
$\mathrm{~B}-\mathrm{NH}{ }^{+}-\mathrm{B}$ or $\mathrm{Q}^{\mathrm{a}}=\mathrm{NH}^{+}-\mathrm{B}$ & 1162 & 1169 & \\
$\mathrm{C}-\mathrm{H}$ bending & & 1126 & 1127 \\
$\mathrm{C}=\mathrm{CH}$ wagging & & 836 & 837 \\
$\mathrm{C}-\mathrm{H}$ bending & 829 & 829 & \\
\hline
\end{tabular}

frequency) when immersed in different analytes; a typical response is shown in the inset of Fig. 6 (a). The observed results for capacitance values are shown for PAni (undoped)/NR LbL thin film with 10 bilayers in Fig. 6.

The most expressive changes were observed in the analytes with free ions in an aqueous solution, such as $\mathrm{H}+$ and $\mathrm{Cl}$ - in an $\mathrm{HCl}$ or $\mathrm{NaCl}$ solution. These ions must interact directly with the polyaniline chains by inducing conformational changes and the doping process. Otherwise, the caffeine and saccharose solutions must interact with the thin film through physical interactions, so detection must occur due to changes in the thin film's capacitance. The measurements also showed a good distinctions between the concentrations from 1 to $50 \mathrm{mM}$, Fig. 6(b), revealing a potential application as a chemical sensor for the LbL PAni/NR films.

\section{Conclusion}

The viability of processing self-assembly LbL films from natural rubber alternated with polyaniline on glass substrates by different mechanisms of adsorption was demonstrated. The growth of the films was successfully observed for $10 \mathrm{~min}$ of immersion and until 10 bilayers. The films fabricated with PAni doped and undoped presented similar physical-chemical characteristics, but their morphologies were quite different. The film's morphology was strongly influenced by the presence of NR particles and can be adjusted by changing the PAni solution's pH. Finally, the potential use of the film as a sensor was evaluated, and significant changes were observed in the film's response to different analytes at very low concentrations. (a)

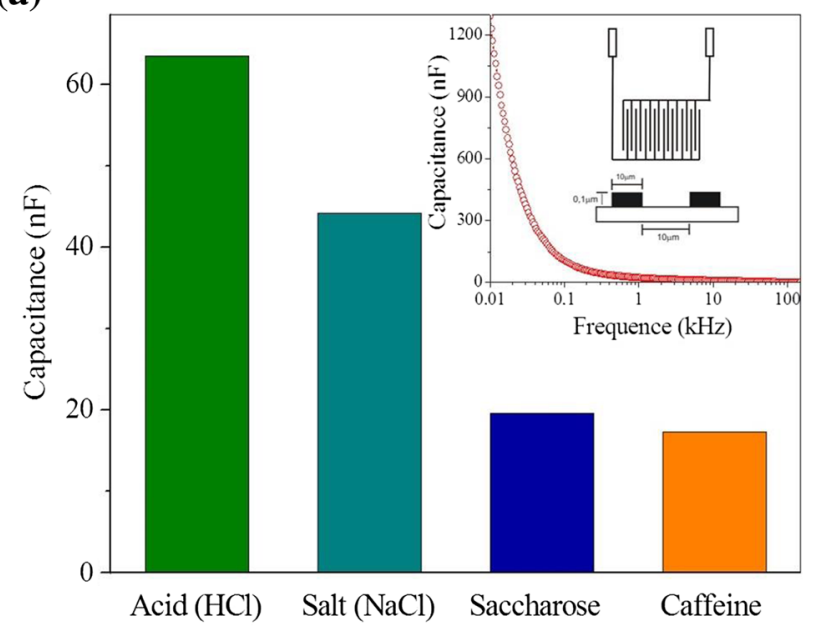

(b)

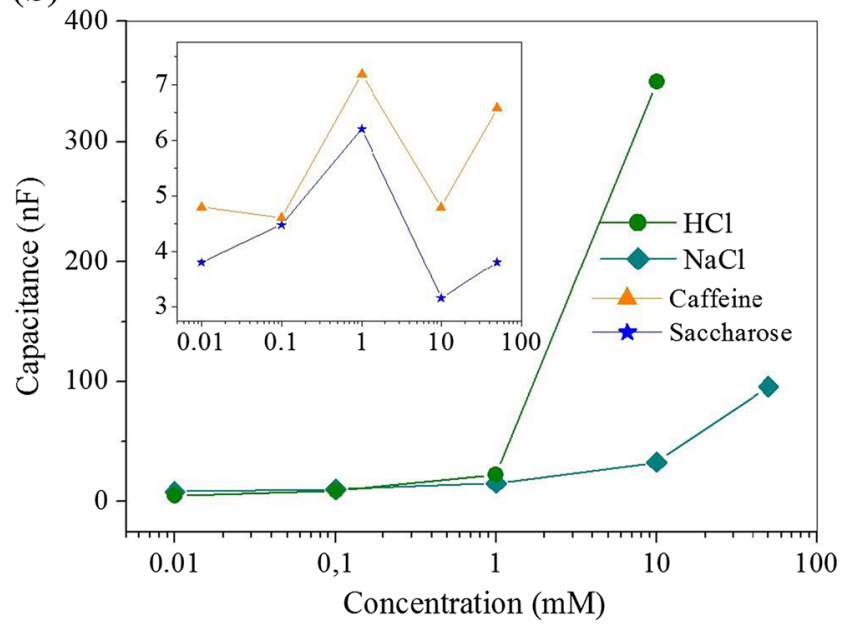

Fig. 6 Capacitance value measured at $1 \mathrm{kHz}$ for different analytes with a solution concentration of $1 \mathrm{mM}$. The inset shows the capacitance measurement in $\mathrm{HCl}$ solution, and the electrode configuration

Acknowledgements FAPESP for financial support; grant number 06/ 01954-4.

\section{References}

1. Farias EAO, Santos MC, Dionisio NA, Quelemes PV, Leite JRSA, Eaton P, Silva DA, Eiras C (2015) Layer-by-layer films based on biopolymers extracted from red seaweeds and polyaniline for applications in elecrochemical sensors of chromium VI. Mat Sci and Eng B 200:9-21

2. Cui S, Wang J, Wang X (2015) Fabrication and design of a toxic gas sensor based on polyaniline/titanium dioxide nanocomposite film by layer-by-layer self-assembly. RSC Adv 5:58211-58219

3. Detsri E, Popanyasak J (2015) Fabrication of silver nanoparticles/ polyaniline composite thin films using layer-by-layer self-assembly technique for ammonia sensing. Coll and Surf A: Phys and Eng Aspects 467:57-65

4. Miyazaki CM, Riul A, dos Santos DS, Ferreira M, Constantino CJL, Pereira-da-Silva MA, Paupitz R, Galvao DS, Oliveira Jr ON 
(2013) Bending of layer-by-layer films driven by an external magnetic field. Inter J of Mol Sci 14:12953-12969

5. Davi CP, Galdino LFMD, Borelli P, Oliveira Jr ON, Ferreira M (2012) Natural rubber latex lbl films: characterization and growth of fibroblasts. J. of Appl. Pol. Sci. 125:2137-2147

6. Decher G (1997) Fuzzy nanoassemblies: toward layered polymeric multicomposites. Science 277:1232-1237

7. Raposo M, Oliveira Jr ON (1998) Adsorption mechanisms in layerby-layer films. Braz J of Phys 28:392-404

8. Mattoso LHC (1996) Polianilinas: síntese, estrutura e propriedades. Quím Nov. 19:388-399

9. Xu DM, Guan MY, Xu QH, Guo Y (2013) Multilayer films of layered double hydroxide/polyaniline and their ammonia sensing behavior. J of Hazard Mat 262:64-70

10. Luo J, Chen Y, Ma Q, Liu R, Liu X (2014) Layer-by-layer assembled ionic-liquid functionalized graphene-polyaniline nanocomposite with enhanced electrochemical sensing properties. J of Mat Chem C 2:4818-4827

11. Li D, Jiang Y, Wu Z, Chen X, Li Y (2000) Self-assembly of polyaniline ultrathin films based on doping-induced deposition effect and applications for chemical sensors. Sensors Actuators B 66: $125-127$

12. Xu XH, Ren GL, Cheng J, Liu Q, Li DG, Chen Q (2006) Selfassembly of polyaniline-grafted chitosan/glucose oxidase nanolayered films for electrochemical biosensor applications. J Mat Sci 41:4974-4977

13. Xie D, Jiang Y, Pan W, Li D, Wu Z, Li Y (2002) Fabrication and characterization of polyaniline-based gas sensor by ultra-thin film technology. Sensors Actuators B 81:158-164

14. Sejdic JT, Soman R, Peng H (2006) Self-assembled polyaniline thin films: comparison of poly(styrene sulphonate) and oligonucleotide as a polyanion. Thin Solid Films 497:96-102

15. Kalasad MN, Gadyal MA, Hiremath RK, Ikram IM, Mulimani BG, Khazi IM, Krishnan SKA, Rabinal MK (2008) Synthesis and characterization of polyaniline rubber composites. Comp Sci and Tech 68:1787-1793

16. Tanaka Y (1991) Recent advances in structural characterization of elastomers. Rubber Chem and Tech 64:325-385

17. Malmonge LF, Mattoso LHC (1995) Electroative blends of poly(vynilidene fluoride) and polyaniline derivatives. Polymer 36:245-249

18. Cheung JH, Stockton WB, Rubner MF (1997) Molecular-level processing of conjugated polymers. 3.Layer-by-layer manipulation of polyaniline via electrostatic interactions. Macromol 30:2712-2716

19. Medeiros ES, Martinez RA, Fonseca FJ, Bernardes-Filho R, Gregorio Jr R, Mattoso LHC (2008) Ultra-thin films of alternating semi-interpenetrating layers of a conducting polymer with thermosetting phenolic resins for sensor application. Sensor Letter 6:1-9

20. Silverstein RM (1979) Identificação espectrométrica de compostos orgânicos, ed. Guanabara Koogan, Rio de Janeiro-RJ

21. Galiani PD, Malmonge JA, Santos DP, Malmonge LF (2007) Compósitos de borracha natural com polianilina. Polímeros: Ciência e Tec 17:93-97

22. Kern W (1984) Purifying $\mathrm{Si}$ and $\mathrm{SiO}_{2}$ surfaces with hydrogen peroxide, inter. Semiconductors:94-99

23. Raposo M, Pontes RS, Mattoso LHC, Oliveira Jr ON (1997) Kinetics of adsorption of poly(o-methoxyaniline) self-assembled films. Macromol 30:6095-6101

24. Wan MX (1992) Absorption-spectra of thin film of polyaniline. J of Poly Sci A 30:543-549

25. Venancio EC, Paterno LG, Filho NC, Borato CE, Firmino A, Mattoso LHC (2005) Influence of the $\mathrm{pH}$ and substrate immersion time on the adsorption of poly(o-ethoxyaniline) in self-assembled films. J Braz Chem Soc 16:558-564

26. Stockton WB, Rubner MF (1997) Molecular-level processing of conjugated polymers. 4. Layer-by-layer manipulation of polyaniline via hydrogen-bonding interactions. Macromol 30: $2717-2725$

27. Zhang YJ, Yang SG, Guan Y, Miao XP, Cao WX, Xu J (2003) Novel alternating polymer adsorption/surface activation selfassembled film based on hydrogen bond. Thin Solid Films 437: 280-284

28. Avlyanov JK, Min Y, Macdiarmid AG, Epstein AJ (1995) Polyaniline: conformational changes induced in solution by variation of solvent and doping level. Synth Met 72:65-71

29. Rippel MM, Leite CAP, Galembeck F (2002) Elemental mapping in natural rubber latex films by electron energy loss spectroscopy associated with transmission electron microscopy. Analy Chem 74: 2541-2546

30. Rippel MM, Lee LT, Leite CAP, Galembeck F (2003) Skim and cream natural rubber particles: colloidal properties, coalescence and film formation. J Coll and Int Sci 268:330-340

31. Paterno LG, Mattoso LHC, Oliveira Jr ON (2001) Filmes poliméricos ultrafinos produzidos pela técnica de automontagem: preparação, propriedades e aplicações. Química Nov. 24:228-235

32. Paterno LG, Mattoso LHC (2002) Influence of different dopants on the adsorption, morphology, and properties of self-assembled films of poly(o-ethoxyaniline). J of Appl Pol Sci 83:1309-1316

33. Tao S, Hong B, Kerong Z (2007) An infrared and Raman spectroscopy study of polyanilines co-doped with metal ions and $\mathrm{H}^{+}$. Spectrochimica Acta-A 66:1364-1368 